\title{
National health research system in Malawi: dead, moribund, tepid or flourishing?
}

\author{
Joses Muthuri Kirigia ${ }^{1 *}$, Damson D Kathyola², Adamson S Muula ${ }^{3}$ and Martin Matthew Okechukwu Ota ${ }^{1}$
}

\begin{abstract}
Background: Several instruments at both the global and regional levels to which countries in the WHO African Region are party call for action by governments to strengthen national health research systems (NHRS). This paper debates the extent to which Malawi has fulfilled this commitment.

Discussion: Some research literature has characterized African research - and by implication NHRS - as moribund. In our view, the Malawi government, with partner support, has made effort to strengthen the capacities of individuals and institutions that generate scientific knowledge. This is reflected in the Malawi national NHRS index (MNSR4HI) of 51\%, which is within the 50\%-69\% range, and thus, it should be characterized as tepid with significant potential to flourish. Governance of research for health (R4H) has improved with the promulgation of the Malawi Science and Technology Act in 2003. However, lack of an explicit R4H policy, a strategic plan and a national R4H management forum undermines the government's effectiveness in overseeing the operation of the NHRS. The mean index of 'governance of R4H' sub-functions was $67 \%$, implying that research governance is tepid. Malawi has a national health research focal point, an R4H program, and four public and 11 private universities. The average index of 'creating and sustaining resources' sub-functions was 48.6\%, meaning that R4H human and infrastructural resources can be considered to be in a moribund state. The average index of 'producing and using research' sub-functions of $50.4 \%$ implies that production and utilization of research findings in policy development and public health practice can best be described as tepid. Efforts need to be intensified to boost national research productivity. Over the five financial years 2011-2016 the government plans to spend $0.26 \%$ of its total health budget on R4H. The mean index of 'financing' sub-functions of $23.6 \%$ is within the range of $1-49 \%$, which is considered moribund.
\end{abstract}

Summary: A functional NHRS is a prerequisite for the achievement of the health system goal of universal health coverage. Malawi, like majority of African countries, needs to invest more in strengthening R4H governance, developing and sustaining $\mathrm{R} 4 \mathrm{H}$ resources, and producing and using research findings.

Keywords: National health research system, Stewardship, Governance, Developing and sustaining resources, Financing, Producing and using research

\section{Background}

Malawi is situated in southern Africa and had an estimated population of 15.4 million in 2011 [1]. It is a low income country and in 2011 had a gross national per capita income of about Int\$ 870 [1]. In 2009, 39\% of the population lived below the international poverty line of less than one United States dollar per day [2]. In 2010, the country lost 12.51 million disability adjusted life

\footnotetext{
*Correspondence: kirigiaj@who.int

${ }^{1}$ Research, Publications and Library Services Programme, Health Systems and Services Cluster, World Health Organization, Regional Office for Africa,

Brazzaville, Congo

Full list of author information is available at the end of the article
}

years (189 877 deaths), of which 8.96 million (71.6\%) were from communicable, maternal, neonatal and nutritional conditions; 2.7 million (21.4\%) from noncommunicable diseases; and 0.88 million (7.0\%) from injuries [3]. Some of the disease burden associated with communicable and noncommunicable diseases could be attributed to the risk factors contained in Table 1.

The Malawi health system's infrastructure comprises 606 health facilities. Of these, $0.7 \%$ are central/tertiary hospitals, $3.8 \%$ district hospitals, $0.3 \%$ mental hospitals, $6.1 \%$ community/rural hospitals, $3.5 \%$ other hospital types, $69.8 \%$ health centers, $12.7 \%$ dispensaries, $2.8 \%$ maternity units, and $0.3 \%$ rehabilitative units. The Christian 
Table 1 Risk factors in Malawi compared to African Region and global averages

\begin{tabular}{|c|c|c|c|c|}
\hline \multicolumn{2}{|l|}{ Health risk factors } & Malawi & African Region & Global \\
\hline \multicolumn{2}{|l|}{ Population using improved drinking-water sources (\%) (2011) } & 84 & 64 & 89 \\
\hline \multicolumn{2}{|l|}{ Population using improved sanitation (\%) (2011) } & 53 & 34 & 64 \\
\hline \multicolumn{2}{|l|}{ Population using solid fuels (\%) (2010) } & $>95$ & 77 & 41 \\
\hline \multicolumn{2}{|l|}{ Preterm birth rate (per 100 live births) (2010) } & 18 & 12 & 11 \\
\hline \multicolumn{2}{|l|}{ Infants exclusively breastfed for the first 6 months of life (\%) (2012) } & 71 & 35 & 38 \\
\hline \multirow[t]{4}{*}{ Children aged $<5$ years (\%) (2012) } & Wasted & 4.1 & 10.4 & 8.0 \\
\hline & Stunted & 47.8 & 40.9 & 25.7 \\
\hline & Underweight & 13.8 & 25.2 & 15.7 \\
\hline & Overweight & 9.2 & 7.9 & 6.6 \\
\hline \multirow[t]{2}{*}{ Prevalence of raised fasting blood glucose among adults aged $\geq 25$ years (\%) (2008) } & Male & 6.4 & 8.3 & 9.2 \\
\hline & Female & 6.2 & 9.8 & 9.2 \\
\hline \multirow[t]{2}{*}{ Prevalence of raised blood pressure among adults aged $\geq 25$ years (\%) (2008) } & Male & 44.5 & 38.1 & 29.2 \\
\hline & Female & 39.4 & 35.5 & 24.8 \\
\hline \multirow[t]{2}{*}{ Adults aged $\geq 20$ years who are obese (\%) (2008) } & Male & 2.6 & 5.3 & 10.0 \\
\hline & Female & 6.2 & 11.1 & 14.0 \\
\hline \multicolumn{2}{|l|}{ Alcohol consumption among adults aged $\geq 15$ years (litres of pure alcohol per person per year) (2008) } & 1.4 & - & - \\
\hline \multirow[t]{2}{*}{ Prevalence of smoking any tobacco product among adults aged $\geq 15$ years (\%) (2009) } & Male & 26 & 17 & 36 \\
\hline & Female & 4 & 3 & 8 \\
\hline \multirow[t]{2}{*}{ Prevalence of current tobacco use among adolescents aged 13-15 years (\%) (2010) } & Male & 17 & 20 & 18 \\
\hline & Female & 11 & 13 & 11 \\
\hline \multirow[t]{2}{*}{ Prevalence of condom use by adults aged 15-49 years during higher risk sex (\%) (2011) } & Male & 25 & - & - \\
\hline & Female & 27 & - & - \\
\hline \multirow[t]{2}{*}{ Population aged 15-24 years with comprehensive correct knowledge of HIV/AIDS (\%) (2011) } & Male & - & 34 & - \\
\hline & Female & - & 28 & - \\
\hline
\end{tabular}

Source: WHO [1].

Health Association of Malawi (CHAM) owns 26.7\% of the facilities, local governments $5.1 \%$, the Ministry of Health $59.6 \%$, the Ministry of Health and CHAM $0.2 \%$, and the Ministry of Health and local government 8.4\% [2]. The health sector has 215 physicians, 2505 nursing and midwifery personnel, 16 dentistry personnel, 107 pharmaceutical personnel, and 88 environment and public health workers [1].

In 2011, per capita total expenditure on health in Malawi was US\$ 30.93 (Int\$ 76.99) [1]. About 73.4\% of total health expenditure came from general government allocations while the remaining $26.6 \%$ was from private sources, of which $53.4 \%$ was household out-of-pocket payments. In 2009, out-of-pocket health expenditure as a proportion of total health expenditure was $10 \%$ [4]. This was fairly lower than what is considered the threshold level of $15-20 \%$, where the incidence of financial catastrophe caused by out-of-pocket health expenses is significant [5]. Donor funding channeled through public and private entities made up $52.4 \%$ of total expenditure on health [6].
Majority of deaths could have been averted if available cost-effective interventions or health services were accessible to those in need of them. But, owing to health system weaknesses, coverage of vital health services is low (Table 2). Research for health $(\mathrm{R} 4 \mathrm{H})$ is essential in development of solutions to overcome health systems weaknesses and in monitoring achievement of the health systems goals of improving health, social and financial risk protection, and health systems' responsiveness and efficiency.

A functioning national health research system (NHRS) is needed to generate scientific knowledge and promote its use in the pursuit of universal health coverage [7]. Such a system could shed light on several pertinent health system issues [8,9] including (a) performance of national and district health systems; (b) leadership and governance of the national health system; (c) design and development of a sustainable health financing system; (d) production, management and retention of health workers; (e) management of medical products, including their planning, procurement, storage, distribution and 
Table 2 Health services coverage in Malawi compared to African Region and global averages

\begin{tabular}{|c|c|c|c|c|}
\hline \multicolumn{2}{|l|}{ Health services } & Malawi & African Region & Global \\
\hline \multicolumn{2}{|l|}{ Unmet need for family planning (\%) (2012) } & 26 & 25 & 12 \\
\hline \multicolumn{2}{|l|}{ Contraceptive prevalence (\%) 2012) } & 46 & 27 & 63 \\
\hline \multicolumn{2}{|l|}{ Antenatal care coverage: at least 4 visits (\%) (2012) } & 46 & 43 & 55 \\
\hline \multicolumn{2}{|l|}{ Births attended by skilled health personnel (\%) } & 71 & 49 & 70 \\
\hline \multicolumn{2}{|l|}{ Births by caesarean section (\%) } & 5 & 4 & 16 \\
\hline \multicolumn{2}{|c|}{ Postnatal care visit within two days of childbirth (\%) (2011) } & 43 & 45 & 49 \\
\hline \multicolumn{2}{|c|}{ Neonates protected at birth against neonatal tetanus (\%) (2011) } & 87 & 77 & 82 \\
\hline \multirow[t]{4}{*}{ Immunization coverage among 1-year-olds (\%) (2011) } & Measles & 96 & 75 & 84 \\
\hline & DTP3 & 97 & 71 & 83 \\
\hline & HepB3 & 97 & 71 & 75 \\
\hline & Hib3 & 97 & 61 & 43 \\
\hline \multicolumn{2}{|c|}{ Children aged 6-59 months who received vitamin A supplementation (\%) (2011) } & 86 & 65 & 50 \\
\hline \multirow[t]{5}{*}{ Children aged $<5$ years (\%) } & With ARI symptoms taken to a health facility (2011) & 70 & 48 & 78 \\
\hline & With ARI symptoms receiving antibiotics (2011) & - & 24 & - \\
\hline & With diarrhoea receiving ORT (ORS and/or RHF) (2011) & 69 & 42 & 64 \\
\hline & Sleeping under insecticide treated nets (2011) & 39 & 32 & - \\
\hline & With fever who received treatment with any antimalarial (2012) & 43 & - & - \\
\hline \multicolumn{2}{|c|}{ Pregnant women with HIV receiving antiretrovirals to prevent MTCT (\%) (2011) } & 53 & 59 & 57 \\
\hline \multicolumn{2}{|c|}{ Antiretroviral therapy coverage among people with advanced HIV infection (\%) (2011) } & 67 & 57 & 54 \\
\hline \multicolumn{2}{|l|}{ Case-detection rate for all forms of tuberculosis (\%) } & 66 & 61 & 67 \\
\hline \multicolumn{2}{|c|}{ Treatment-success rate for smear-positive tuberculosis (\%) } & 87 & 82 & 87 \\
\hline
\end{tabular}

Source: WHO [1].

dispensing; (f) development and evaluation of new health technology; (g) economic efficiency of health facilities; (h) attitudinal, cultural, geographical, communication and socioeconomic barriers to health services access; (i) costeffective ways of scaling up essential health interventions; (j) equity in distribution of health inputs, services and costs; (k) feasibility of various options for attaining universal health coverage; and (l) multisectoral action to address determinants of health.

Global and regional instruments such as the 2010 Sixty-third World Health Assembly [10], the 2008 Bamako Call for Action [11], the 2008 Algiers Declaration [12], the 2006 Abuja and Accra communiques [13,14], the 2005 Fifty-eighth World Health Assembly [15], the 2004 Mexico Ministerial Summit statement [16], and the 1998 Forty-eighth WHO Regional Committee for Africa [17] urged national governments to build and strengthen NHRS to promote the generation of scientific knowledge and promote its utilization in health policy development, planning and decision making.

In 2011, the Malawi Ministry of Health developed a national health sector strategic plan 2011-2016 with the objective to coordinate and regulate health research in such a way that it generates information that will inform policy (and plan) development and evidence-based decision making in programme implementation [2]. Four strategies are stated in the strategic plan for achieving this research objective: to build capacity for high-quality health research at all levels, to strengthen the governance and stewardship role of the health ministry in the conduct of health research, to mobilize resources for health research, and to promote the utilization of research findings for policy and program formulation [2]. Although not explicitly stated, the first objective also covers developing and sustaining $\mathrm{R} 4 \mathrm{H}$ resources, and the last objective includes production of research.

This paper debates the questions: To what extent has Malawi implemented the commitments it made at global and regional forums to improve performance of its NHRS? Is the Malawian NHRS dead, moribund, tepid or flourishing? The specific objective is to debate the extent to which Malawi has strengthened its NHRS.

\section{Discussion}

NHRS conceptual framework

A NHRS is the people, institutions and activities whose primary purpose is to generate and promote utilization of high-quality scientific knowledge to promote, restore and/or maintain the health status of populations [18]. 
Figure 1 shows the framework of a NHRS. Its goals are to advance scientific knowledge and promote its utilization in augmenting the performance of the national health system in the achievement of its ultimate objectives of improving health, social and financial risk protection, and health systems' responsiveness and efficiency. A NHRS has four functions: governance, developing and sustaining resources, financing, and producing and using $\mathrm{R} 4 \mathrm{H}$. Information on the status of the four functions was collected by the Malawi national focal point for $\mathrm{R} 4 \mathrm{H}$ (DDK - co-author) using the questionnaire developed and pilot tested by Kirigia and Wambebe [19] and subsequently applied in 2008 by Bondji et al. [20]. The questionnaire covered topics relating to health research policy, legislation and strategic planning; research coordination mechanisms; health research programs; research institutes; national universities; research financing and budget; involvement of nongovernmental organizations in research; and actions needed to strengthen health research capacity.
Much of the information on financing for $\mathrm{R} 4 \mathrm{H}$ and production and use of research was garnered through review of relevant published and unpublished literature. The information was gathered primarily to underpin the debate and not to generate comprehensive "hard" evidence on the Malawian NHRS.

\section{Governance of $\mathrm{R} 4 \mathrm{H}$}

Government oversight of $\mathrm{R} 4 \mathrm{H}$ involves defining the NHRS vision, setting national priorities and overseeing adherence to them, developing and monitoring ethical standards for health research and research partnerships, and monitoring and evaluating the entire NHRS [18]. Specifically, R4H governance concerns development of national health policy and health strategic plan, $\mathrm{R} 4 \mathrm{H}$ policy and strategic plan, $\mathrm{R} 4 \mathrm{H}$ agenda, $\mathrm{R} 4 \mathrm{H}$ legislation, codes of conduct, and ethical standards and guidelines. It includes managing the establishment of a national health research management forum; national, institutional and hospital ethical review committees to protect the dignity, integrity and safety of research participants;

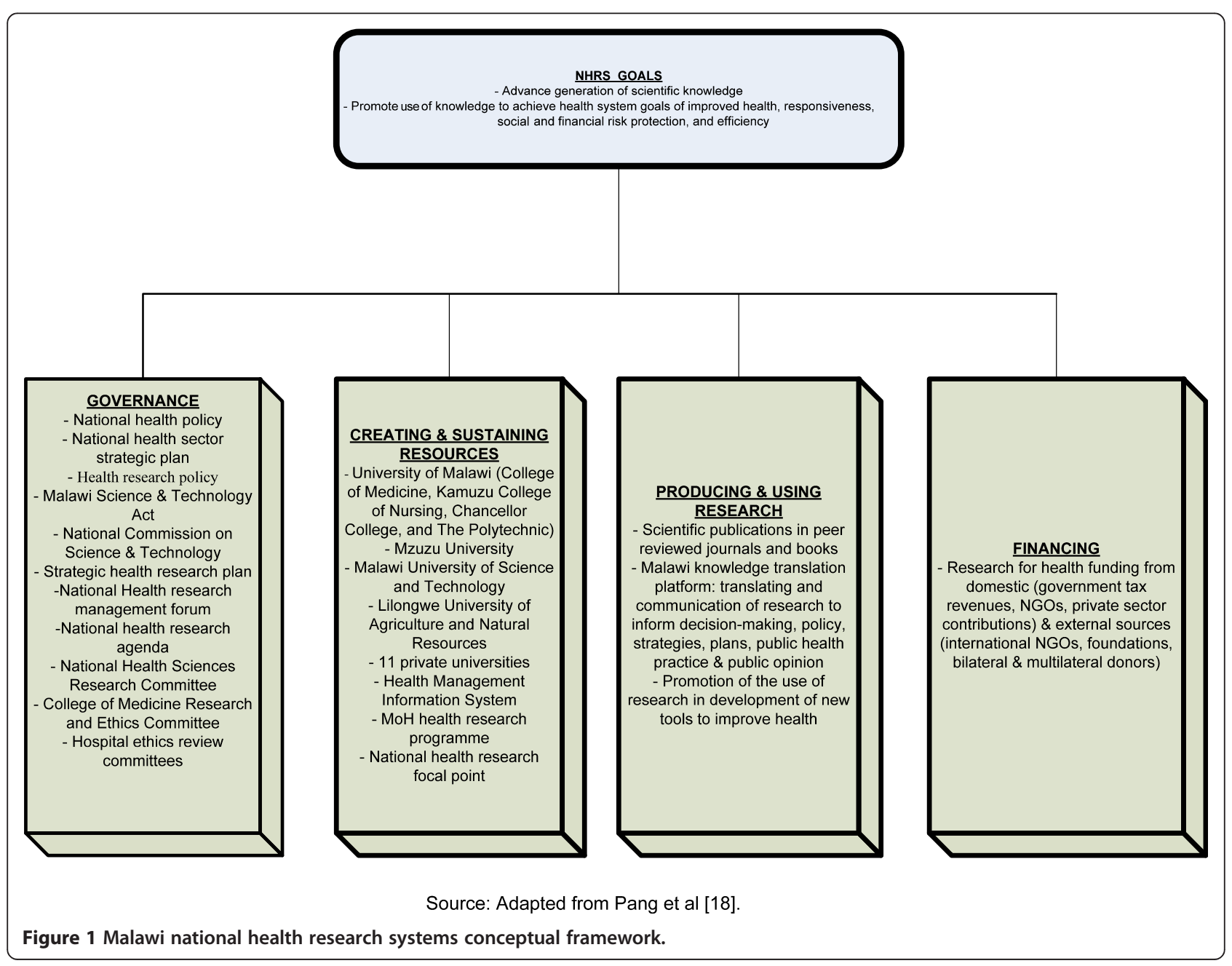


national and institutional scientific review committees to ensure scientific rigor of research protocols and their implementation; and the national network for R4H. Designation of a national $\mathrm{R} 4 \mathrm{H}$ focal point is required to act as a point of reference for all issues relating to health research. Governance is an overarching function of the government, aiming to ensure effective supervision, coalition building, system design, accountability and regulation for all $\mathrm{R} 4 \mathrm{H}$ taking place in both public and private sectors [21]. Table 3 shows the NHRS components in Malawi.

Malawi has a national health policy, a strategic health plan, and a health research agenda but not a valid $\mathrm{R} 4 \mathrm{H}$ policy or a strategic $\mathrm{R} 4 \mathrm{H}$ plan. The law on health research, the Malawi Science and Technology Act that was promulgated in 2003, encapsulates ethical considerations and other guidelines [22]. The country does not have a functional health research management forum.

The National Commission on Science and Technology (NCST) regulates the conduct of research by the various

Table 3 NHRS components in Malawi

\begin{tabular}{|c|c|}
\hline NHRS component & Present or not \\
\hline National health policy & Yes \\
\hline Strategic health plan & Yes \\
\hline Health research policy & No \\
\hline Law relating to health research & Yes \\
\hline Law includes ethical concerns & Yes \\
\hline Strategic health research plan & No \\
\hline National health research management forum & No \\
\hline Functional ethical review committee & Yes \\
\hline Functional scientific review committee & Yes \\
\hline Institutions with institutional review committees & Yes \\
\hline Hospitals with ethical review committees & Yes \\
\hline National health research focal point in the country & Yes \\
\hline $\begin{array}{l}\text { Guidelines for development of collaboration } \\
\text { agreements on health research involving health } \\
\text { institutions and agencies outside the country }\end{array}$ & Yes \\
\hline Health research program & Yes \\
\hline National health research agenda & Yes \\
\hline Health research program action plan & Yes \\
\hline Knowledge translation platform & Yes \\
\hline Health research program conducts research & No \\
\hline National health research institute(s) or council & No \\
\hline $\begin{array}{l}\text { Universities with faculties of health sciences that } \\
\text { conduct research }\end{array}$ & Yes \\
\hline $\begin{array}{l}\text { Faculties of health sciences with memorandum } \\
\text { of understanding with Ministry of Health }\end{array}$ & Yes \\
\hline $\begin{array}{l}\text { Budget line for research for health in Ministry of } \\
\text { Health budget }\end{array}$ & Yes \\
\hline NGOs that undertake health research & Yes \\
\hline
\end{tabular}

institutions in Malawi. It has delegated powers to the National Health Sciences Research Committee and the College of Medicine Research and Ethics Committee (COMREC) to review study proposals to ensure methodological and scientific rigor of research protocols and approve health-related research. COMREC and hospital ethical review committees appraise all clinical research proposals to protect the integrity and safety of persons participating in research [22]. Malawi has national guidelines on health research collaborative agreements involving external health institutions and agencies.

What are the implications for Malawi of the absence of a research management forum, which is governance and management mechanism, and a health research policy and a strategic plan, which are the foundations of a NHRS?

Malawi, like any other country, requires an overarching health research management forum with representation of all key stakeholders, including the ministries of education and science and technology, the private sector, health development partners, NGOs, civil society, and the media, and with the Ministry of Health as its Secretariat. Some of its terms of reference could be to (a) advice on national health research policies, strategies and priorities; (b) coordinate R4H; (c) prepare rolling annual national health research plans and monitor and evaluate their implementation; (d) promote the development of health research activities; (e) review $\mathrm{R} 4 \mathrm{H}$ management and suggest strategies to overcome problems in implementation of policies; (f) propose mechanisms to nurture a scientific environment to attract talent and develop human resources for $\mathrm{R} 4 \mathrm{H}$; and (g) facilitate dissemination and translation of research results into products, policies and programs aimed at improving health [23,24]. The health research management forum is a vital organ that helps ensure that the government is in the driver's seat of $\mathrm{R} 4 \mathrm{H}$ and that research in the country is harmonized and aligned with the national $\mathrm{R} 4 \mathrm{H}$ policy and agenda.

A $\mathrm{R} 4 \mathrm{H}$ policy is an essential tool for the government, and when properly formulated in consultation with all relevant stakeholders and implemented through plans and programs, it might have substantial impact on the effectiveness of the NHRS and performance of the national health system. The policy is an official government statement conveying the vision, values, principles, objectives and areas of action to improve the achievement of NHRS' goals. Its formulation will involve several steps such as (a) gathering information and data for policy development; (b) gathering evidence for effective strategies, including learning from other countries' experiences; (c) political consultation and negotiation with key stakeholders; (d) definition of the policy vision, values, principles and objectives; (e) translation of objectives 
into broad areas of action; and (f) identification of the major roles and responsibilities of the various sectors [25]. In short, a policy serves to provide a vision that all stakeholders can rally around and strategic direction for $\mathrm{R} 4 \mathrm{H}$ that ensures focus on national research priorities.

Health researchers [26,27], policy-makers [10,17,28] and institutions $[29,30]$ consider R4H policy as important for governance and performance of an NHRS. The landmark Mexico City Ministerial Summit on Health Research of November 2004 [15] and the Bamako Ministerial Summit on Research for Health called upon governments to establish and implement a national health research policy [11]. Our literature exploration did not reveal evidence of a correlation between the existence of a $\mathrm{R} 4 \mathrm{H}$ policy and research activity or impact on health indicators. However, we hypothesize that the lack of a nationally agreed upon $\mathrm{R} 4 \mathrm{H}$ policy might partially explain why, for example the USA, whose healthy life expectancy is 70 years, is nine and eight years lower than those of Japan and Sweden, respectively (see Table 4) [1] in spite that USA's per capita total expenditure on health is more than double that of those two countries. Even though the USA had the largest number of publications in 2010, Sweden had a higher research output per person in the population [1,31]. Japan, on the other hand, had a lower number of publications per person. So, even though its research output per person is lower than that of the USA, Japan's policy to guide research contributes to ensuring that majority of the research findings are used in

\begin{tabular}{|c|c|c|c|}
\hline Countries & $\begin{array}{l}\text { Healthy life } \\
\text { expectancy }\end{array}$ & $\begin{array}{l}\text { Per capita total } \\
\text { expenditure on } \\
\text { health (PPP Int\$) }\end{array}$ & $\begin{array}{l}\text { Publications } \\
\text { per person }\end{array}$ \\
\hline Denmark & 70 & 4456 & 0.00209 \\
\hline Sweden & 78 & 3938 & 0.00208 \\
\hline Netherlands & 71 & 5118 & 0.00183 \\
\hline Finland & 71 & 3382 & 0.00181 \\
\hline Australia & 73 & 3890 & 0.00168 \\
\hline Singapore & 75 & 2556 & 0.00166 \\
\hline Canada & 72 & 4551 & 0.00154 \\
\hline UK & 71 & 3364 & 0.00143 \\
\hline Austria & 71 & 4795 & 0.00133 \\
\hline Germany & 71 & 4474 & 0.00105 \\
\hline USA & 70 & 8467 & 0.00104 \\
\hline France & 72 & 4128 & 0.00097 \\
\hline Japan & 79 & 3415 & 0.00057 \\
\hline
\end{tabular}

Source: WHO [1] and Pouris [31]. Note: Publications per person equals total number of publications in 2010 divided by total population. the development of health technologies, and, hence, to improve healthy life expectancy.

The strategic $\mathrm{R} 4 \mathrm{H}$ plan is a document containing national health research strategies, timeframes, indicators and targets, detailed activities by each area of action, estimates of capital and recurrent costs per strategic area, and resources and budget for each year of the plan. The strategic plan is implemented through rolling annual work plans and accompanying annual budgets. Developing the strategic plan involves a number of steps: (a) preparing to develop the plan by gathering the requisite resources, (b) clarifying the mandate and scope of work, (c) analysing external and internal environments, (d) identifying strategic issues, (e) defining the strategic aims and the strategies to address each strategic aim, (f) identifying the resources required to achieve the strategic aims, (g) drawing up an internal capacity building plan, and (h) costing the plan $[24,32]$.

Lack of an explicit R4H policy, a strategic plan or a health research management forum emasculates the government's effectiveness in supervising the NHRS. The Malawi health sector's strategic plan acknowledges that the absence of legal and policy frameworks to regulate research and the weak coordination and monitoring of research being carried out in the country pose major challenges to NHRS governance [2]. To address those challenges, the national health sector's strategic plan has as its research objective to "... coordinate and regulate health research in such a way that it generates information that will inform policy development and evidencebased decision making in programme implementation" ([2] p. 69).

The Ministry of Health plans to strengthen its governance role in $\mathrm{R} 4 \mathrm{H}$ through six interventions: (a) implementing the national health research agenda; (b) developing and implementing a national health research policy; (c) supporting the National Health Sciences Research Committee in the review and approval of research proposals; (d) establishing a national public health institute in the Community Health Sciences Unit with leadership over public health research as one of its core functions; (e) ensuring that all health research institutions sign a memorandum of understanding with the health ministry; and (f) supporting regular inspection of and monitoring visits for all health research institutions [2].

\section{Developing and sustaining $\mathrm{R} 4 \mathrm{H}$ resources}

Developing and sustaining $\mathrm{R} 4 \mathrm{H}$ resources includes building, reinforcing and sustaining of (a) human resources for research in biomedical, bioscience, epidemiology, social science and health systems areas; (b) physical infrastructure; and (c) institutional and systemic capacities to manage knowledge. Malawi has a national health research focal point and a $\mathrm{R} 4 \mathrm{H}$ program housed within the Ministry of 
Health. The program has a health research mission statement, clearly defined terms of reference and an organizational structure. It has five technical and three support staff. Each technical staff in the program has a computer, an essential research tool. The program has e-mail and internet connectivity, so researchers can easily network and collaborate with peers within and outside the country, access pertinent data and literature from around the world and submit their manuscripts online for publishing.

Malawi has four public universities: the University of Malawi comprising the College of Medicine, the Kamuzu College of Nursing, Chancellor College, and the Polytechnic; Mzuzu University; Malawi University of Science and Technology; and Lilongwe University of Agriculture and Natural Resources. There are 11 private universities with varied capacities [33]. For example, the Catholic University of Malawi, the Malawi Adventist University and the University of Livingstonia were ranked 19 590, 21117 and 21 276, respectively, among universities worldwide [34]. Whereas some colleges and research centres in the public universities have relatively strong capacity for $\mathrm{R} 4 \mathrm{H}$, that capacity in private universities is moribund. Nevertheless, all public and private universities constitute pillars upon which requisite $\mathrm{R} 4 \mathrm{H}$ capacities could be built or strengthened. The faculties of health sciences in the public universities do not have memoranda of understanding with the Ministry of Health. Such memoranda could have been for developing human resources, providing technical advice, or undertaking research for the ministry. We concur with Nachega et al. [35] that African countries with limited levels of human resources for health research like Malawi ought to invest more in postgraduate training programs in epidemiology and public health. In addition, we share their view that African countries could accelerate building of a critical mass of epidemiologists through SouthSouth and North-South collaboration.

Cognizant of the weakness in its resources for $\mathrm{R} 4 \mathrm{H}$, the Government of Malawi initiated the Health Research Capacity Strengthening Initiative with the support of the United Kingdom's Department for International Development, Wellcome Trust and International Development Research Centre, with an overall goal of building and strengthening individual and institutional health research capacity. At the individual level, the initiative provides training fellowships, research grants, small grants, internships and $\mathrm{PhD}$ bursaries. For institutions, the initiative offers institutional grants and small grants for undergraduate dissertation work [36,37]. The initiative supported capacity strengthening at Chancellor College, the College of Medicine, the Polytechnic, Mzuzu University, Kamuzu College of Nursing, and Bunda College (now part of the Lilongwe
University of Agriculture and Natural Resources). Program evaluation during August-October 2013 revealed that the initiative supported about $50 \mathrm{MSc}$ and $\mathrm{PhD}$ students and over 400 undergraduate health-related projects in areas ranging from basic science to biomedical and social science [38]. Thus, the initiative has contributed to raising the number of scientists in Malawi and to promoting research interest among young Malawians. Malawi currently does not a have health research institute or council, and probably, as recommended by Mayosi and colleagues [39] for South Africa, new funding should be directed at developing such health research infrastructure.

The Ministry of Health plans to leverage the capacities developed by the Health Research Capacity Strengthening Initiative to build capacity for high quality health research at all levels of the national health system. That will be done through training of district health management teams and program staff in research methods applied to health systems and public health [2]. Furthermore, the ministry plans to ensure that monitoring, evaluation and epidemiology work, including surveillance, are strengthened and that the functionality of the health management information system is improved [2]. The objective is to provide reliable, complete, accessible, timely and consistent health-related information and ensure that it is used for evidence-based decision making at all levels of the health system.

\section{Producing and using R4H}

The Malawi National Health Research Agenda 20122016 contains research priorities organized under nine disease and non-disease thematic areas: communicable diseases, noncommunicable diseases, sexual and reproductive health, trauma, mental health, nutrition, environmental health, health systems, and community system strengthening. The research priorities for each of the disease-based areas are categorized into epidemiology, prevention, diagnostics and treatment [2].

The health research program does not undertake research by itself but mainly identifies research needs and coordinates research work, for which it has a plan of action. Majority of $\mathrm{R} 4 \mathrm{H}$ is conducted by the College of Medicine and Mzuzu University. Malawi does not have a national health research institute or council. According to the national health sector strategic plan 2011-2016, one of the persistent challenges is the limited multidisciplinary research, largely owing to the lack of highly qualified and experienced indigenous researchers [2]. However, that is improving. For example, between 2008 and 2013, aside from undergraduate projects, the Health Research Capacity Strengthening Initiative funded 15 doctor of philosophy, 41 Master of Science, 3 junior and 7 senior researchers, 1 multidisciplinary and 10 intern 
research projects. Out of the 77 projects, $49 \%$ were in biomedical science (clinical chemistry, microbiology, molecular, bio-statistics), $26 \%$ in public or international health (epidemiology, demography and informatics) and $25 \%$ in social science (anthropology and economics). By October 2013, 50\% of the grantees had presented research results in conferences, $50 \%$ had submitted manuscripts for publication in various international journals and $6 \%$ had published papers in international journals [38].

During 2005-2012 the University of Malawi published a total of 443 articles in international journals [30]. About 215 (48.5\%) of those were on a health subject, and of these $66 \%$ were by the College of Medicine, $10.7 \%$ by Kamuzu College of Nursing, $16.3 \%$ by Chancellor College, $3.7 \%$ by the Polytechnic and $3.3 \%$ by Bunda College of Agriculture. A limitation of the bibliometric study by Kakhongwe [40] was that it did not include articles published in national academic journals.

Uthman and Uthman's [41] analysis of African countries' biomedical papers indexed by PubMed between 1996 and 2005 showed that Malawi had a total of 450 articles, ranking 15 in contributions among the African countries indexed. Malawi had a relative growth of $67.6 \%$

Muula [42] quantified the publications from Kamuzu College of Nursing faculty since its opening in 1979 to mid-2006 indexed in Medline/PubMed, Psychinfo and Web of Science and found that 57 faculty members had contributed a total of 42 articles or there were 0.74 articles per faculty member. He attributed the low scholarly output to high teaching loads, lack of graduate study opportunities with $35 \%$ of staff having only an undergraduate degree, lack of research training, lack of competition from any other nursing school, lack of research funding, and dearth of role models.

Gondwe and Kavinya's [43] search of the MEDLINE/ PubMed database found 489 health articles originated from Malawi between 1996 and 2006. About 20.9\% of these had Malawian first authors. There was a $103 \%$ increase in articles published in the 10 year period [43]. Clearly, those conducting $\mathrm{R} 4 \mathrm{H}$ in Malawi have made commendable strides over the years, and they should be encouraged to intensify their efforts [44].

Malawi has a relatively new platform that brings together policy-makers, subject experts and researchers and that is designed for translating, synthesizing and communicating research to inform health policy and practice. That is expected to change the current landscape characterized by limited utilization of health research findings in practice and policy formulation owing to the limited interaction between researchers and users of the research findings [2]. For example, the University of Malawi and Mzuzu University, the two national universities with faculties of health sciences, did not have a memorandum of understanding with the Ministry of Health until recently. The main avenues for disseminating research findings have been national and institutional meetings, academic print media, conferences and scientific journals. However, very few policy-makers participate in these forums, and in many cases the dissemination process does not target or address the needs of non-technical policy-makers.

To promote the utilization of research findings for policy and program formulation, the health ministry plans to (a) create a website for the Research Unit and the National Health Sciences Research Committee; (b) establish a health policy analysis unit to produce policy briefs and newsletters; (c) require that national universities with faculties of health sciences such as the College of Medicine, Mzuzu University and Malawi College of Health Sciences implement the memorandum of understanding with the ministry; (d) develop leadership capacity for the integration of public health research into policy formulation and program planning; (e) organize annual conferences for dissemination of health research findings; and (f) promote evidence-based policy debates. The NCST is in the process of developing a registry of research to capture protocols and ethics submissions and to track fulfilment of the research agenda [38].

There will be need in future for an up-to-date bibliometric study that analyses in details Malawi's health research performance over a period of one decade. Unlike the Kakhongwe study [40], the suggested study should include all articles published in national and international journals. Examples of such studies are those by Pouris [31], Senkubuge and Mayosi [21], Schneider [45] and the World Bank and Elsevier [46]. In addition, in order to monitor the alignment of research with the national $\mathrm{R} 4 \mathrm{H}$ priority agenda, there is need for studies that compare the actual published research with national research priorities.

\section{Financing of R4H}

In this paper financing refers to estimation of recurrent and capital cost of $\mathrm{R} 4 \mathrm{H}$; mobilization of funds for $\mathrm{R} 4 \mathrm{H}$ from individuals, businesses including for-profit private firms and private non-profit organizations, government, bilateral and multilateral partners. and international foundations; accumulation and management of $\mathrm{R} 4 \mathrm{H}$ funds; allocation of funds to individuals, institutions and networks within NHRS's that govern and create R4H inputs and produce, monitor and evaluate $\mathrm{R} 4 \mathrm{H}$; and tracking expenditure on $\mathrm{R} 4 \mathrm{H}$.

In Malawi, $\mathrm{R} 4 \mathrm{H}$ is primarily financed by the government and international nongovernmental organizations and to a lesser extent by multilateral and bilateral 
donors. Various mechanisms exist for funding health research, including institutional grants usually targeted at students and faculty in tertiary education institutions; national small grants that target the general research fraternity; and commissioned research grants from government departments, donors, nongovernmental organizations and public-private partnerships. The government plans to create a national health research fund to pool resources from the government and development partners for research in priority areas. The fund will be managed by the Ministry of Health.

The Ministry of Health has a budget line for research for health. Over the five-year financial period 2011/122015/16 Malawi budgeted 521 million Malawi kwacha (US\$ 3.42 million) for improving the functioning of the health management information system to provide reliable, complete, accessible, timely and consistent healthrelated monitoring and evaluation information, and 139 million kwacha (US\$ 0.913 million) for implementing the national health research agenda [2]. The budget document estimates that ideally to execute the activities planned under monitoring and evaluation type of research would require 782 million kwacha (US\$ 5.15 million), and implementation of the research agenda would need 209 million kwacha (US\$ 1.37 million). This is an acknowledgment that the $\mathrm{R} 4 \mathrm{H}$ budget has a deficit of about 331 million kwacha (US\$ 2.17 million).

The planned budget for research for the 2011/12$2015 / 16$ financial years is approximately $0.26 \%$ of the total government budget of 252.154 billion kwacha (US\$ 1.66 billion million) (Table 5) [2]. In the 2012/ 2013 financial year the Ministry of Health spent 28 million kwacha (US\$ 0.18 million) on R4H (monitoring and evaluation was not included), which was $0.78 \%$ of the overall health budget of 3.6 billion kwacha (US\$ 23.64 million) [47]. These figures do not include research and development expenditures by the commercial or private sector market, global health initiatives such as the Global Fund to Fight AIDS, Tuberculosis and Malaria, the GAVI Alliance and the Global Health Initiative or philanthropic contributions from private and public partners.
As Senkubuge and Mayosi [21] report for South Africa in their study on the state of NHRS in that country, Malawi also grossly under-invests in $\mathrm{R} 4 \mathrm{H}$. There is need, therefore, for the Ministry of Health to continue advocating to have $2 \%$ of the national health budget spent on research, in line with the recommendations of the Commission on Health Research for Development [48] and as endorsed by the ministers of health in Abuja [13], Accra [14], Algiers [12] and Bamako [11]. Advocacy is needed to have at least $5 \%$ of the health sector project and program aid from development aid agencies earmarked for $\mathrm{R} 4 \mathrm{H}$ capacity strengthening as recommended by the Commission on Health Research for Development [48] and reiterated by the Fifty-eighth World Health Assembly [15].

We concur with Senkubuge and Mayosi [21] and Mayosi et al. [39] that to develop a robust NHRS every country requires a functional monitoring and evaluation mechanism created within existing $\mathrm{R} 4 \mathrm{H}$ structures to serve a feedback-loop role. Such a mechanism is already being used in the Organization for Economic Co-operation and Development (OECD) countries [49], and, in fact, an annex in the OECD Frascati manual is considered relevant for developing countries and has been proposed for use in measuring their research and development programs [50]. Malawi needs to adapt the OECD mechanism to review its health needs, assess health-related research and development opportunities and status, and monitor expenditure on health-related research, development and innovation for financial resources from all sources, including the government, higher education, global health initiatives, philanthropic institutions and industry.

\section{Malawi NHRS index}

The Malawi $\mathrm{R} 4 \mathrm{H}$ system of has four functions under which fall 30 sub-functions. Taking into account the information contained in the completed questionnaire on the Malawi health research program (see the "NHRS conceptual framework" section), we assessed the subfunctions and allocated them a percentage score ranging from $0 \%$, if they were non-existent or dead, to $100 \%$, if

Table 5 Malawi government's R4H budget estimates for the HSSP period 2011-2016

\begin{tabular}{|c|c|c|c|c|c|c|c|}
\hline \multirow[t]{2}{*}{ Broad activities } & \multicolumn{7}{|c|}{ Estimated budget (Malawi kwacha million) } \\
\hline & $2011 / 12$ & $2012 / 13$ & $2013 / 14$ & $2014 / 15$ & $2015 / 16$ & Total & Ideal cost 2011-16 \\
\hline (A) M\&E - development and research & 88 & 94 & 103 & 108 & 127 & 521 & 782 \\
\hline (B) Implement national health research agenda & 24 & 25 & 28 & 29 & 34 & 139 & 209 \\
\hline (C) Total $(A+B)$ & 112 & 119 & 131 & 137 & 161 & 660 & 991 \\
\hline (D) Total for health budget & 35861 & 48867 & 55211 & 50485 & 61730 & 252154 & 632645 \\
\hline$\%=(C / D)^{*} 100$ & 0.312 & 0.244 & 0.237 & 0.271 & 0.261 & 0.262 & 0.157 \\
\hline
\end{tabular}

Source: Government of Malawi [2]. 
their performance was excellent or they were flourishing (see Figure 2). The Malawi national system of research for health index (MNSR4HI) that we constructed is the sum of the 30 sub-functions (SFI) indices listed in Table 6 divided by 30 and multiplied by $100 \%$.

All the indices for the individual sub-functions were calculated using the following general formula:

$$
\text { Sub function index }=\left(\frac{\text { Actual xi score-Minimum xi Score }}{\text { Maximum xi score-Minimum xi score }}\right) \text {, }
$$

Where $x_{i}$ is the $i^{\text {th }}$ sub-function, such as the existence of a national policy on research for health (NPR4H), a strategic plan on research for health, a national research for health priority list/agenda, a national ethics review committee, institutional ethical review committees, a national $\mathrm{R} 4 \mathrm{H}$ management forum, a law governing research, a national scientific research committee, etc. For instance, the national policy on research for health index (R4HPI) was calculated as follows:

$$
R 4 H P I=\left(\frac{\text { Actual } R 4 H P-\text { Minimum } R 4 H P}{\text { Maximum R4HP-Minimum } R 4 H P}\right),
$$

Where Actual R4HP is the actual research for health policy score, Minimum R4HP is the minimum research for health policy score, and Maximum R4HP is the maximum research for health policy score. As an example, if we assume that the regional minimum R4HP score is 0 , the maximum score is 100 and the actual average R4HP score in Table 6 is 100, the R4HPI can be obtained as follows:

$$
R 4 H P I=\left(\frac{100-0}{100-0}\right)=1 .
$$

Similarly, the national ethics review committee index (NERCI) was estimated as follows:

$$
N E R C I=\left(\frac{\text { Actual NERC }- \text { Minimum NERC }}{\text { Maximum NERC-Minimum NERC }}\right)
$$

Where Actual NERC is the actual national ethics review committee (NERC) score (i.e. an average of the score from the Department of Research at the Ministry of Health and Dr Adamson Muula of the College of Medicine), Minimum NERC is the minimum NERC score, and Maximum NERC is the maximum NERC score. For example, if we assume that the regional minimum NERC score is 0 , the maximum score is 100 and the actual average NERC score in Table 6 is 88, NERCI can be obtained as follows:

$$
N E R C I=\left(\frac{88-0}{100-0}\right)=0.88 .
$$

The indices for all the sub-functions were estimated in this way. Out of 30 sub-functions, 4 had an index of zero

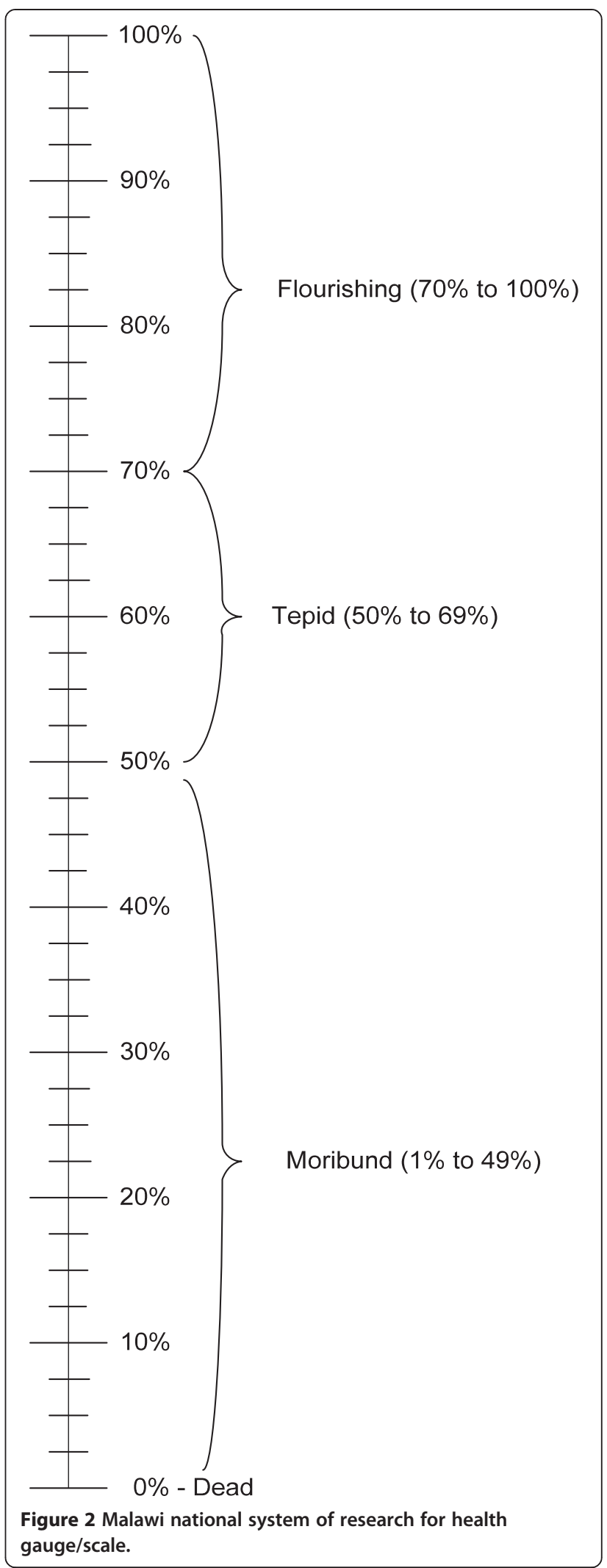


Table 6 Malawi national system of research for health index (MNSR4HI)

\begin{tabular}{|c|c|c|c|c|}
\hline Functions & $\begin{array}{l}\text { Actual } \\
\text { score }(A)\end{array}$ & $\begin{array}{l}\text { Maximum } \\
\text { score (B) }\end{array}$ & $\begin{array}{l}\text { Minimum } \\
\text { score (C) }\end{array}$ & $\begin{array}{l}\text { Sub-function index } \\
(D)=(A-C) /(B-C)\end{array}$ \\
\hline \multicolumn{5}{|l|}{ Governance of research for health } \\
\hline National health policy & 100 & 100 & 0 & 1 \\
\hline National health sector strategic plan & 100 & 100 & 0 & 1 \\
\hline National policy on research for health & 0 & 100 & 0 & 0 \\
\hline Strategic plan on research for health & 0 & 100 & 0 & 0 \\
\hline Law governing research & 95 & 100 & 0 & 0.95 \\
\hline National research for health priority list/agenda & 98 & 100 & 0 & 0.975 \\
\hline National ethics review committee & 90 & 100 & 0 & 0.9 \\
\hline Institutional ethical review committees & 88 & 100 & 0 & 0.875 \\
\hline National R4H management forum & 50 & 100 & 0 & 0.5 \\
\hline National scientific research committee & 50 & 100 & 0 & 0.5 \\
\hline \multicolumn{5}{|l|}{ Developing and sustaining resources } \\
\hline University colleges of health sciences conducting research & 78 & 100 & 0 & 0.775 \\
\hline $\begin{array}{l}\text { Availability of memorandum of understanding between university and ministry of } \\
\text { health }(\mathrm{MoH})\end{array}$ & 38 & 100 & 0 & 0.375 \\
\hline National health research institute(s) or council & 0 & 100 & 0 & 0 \\
\hline Private universities conducting research for health & 15 & 100 & 0 & 0.15 \\
\hline Health Management Information System doing regular monitoring and evaluation & 50 & 100 & 0 & 0.5 \\
\hline Health research programme at $\mathrm{MoH}$ & 80 & 100 & 0 & 0.8 \\
\hline National health research focal point & 75 & 100 & 0 & 0.75 \\
\hline Public health laboratories & 48 & 100 & 0 & 0.475 \\
\hline Libraries with access to latest journal issues & 55 & 100 & 0 & 0.55 \\
\hline \multicolumn{5}{|l|}{ Producing and using research } \\
\hline Existence of knowledge translation platform & 40 & 100 & 0 & 0.4 \\
\hline Peer reviewed publications per person in population (compared to AFR average) & 38 & 100 & 0 & 0.375 \\
\hline Use of research in development of new tools to improve health & 25 & 100 & 0 & 0.25 \\
\hline Availability of computers in research programme & 73 & 100 & 0 & 0.725 \\
\hline Availability of internet connectivity in research programme & 83 & 100 & 0 & 0.825 \\
\hline Number of technical staff in a research for health programme & 45 & 100 & 0 & 0.45 \\
\hline \multicolumn{5}{|l|}{ Financing } \\
\hline Existence of a budget line in the health budget for research for health & 60 & 100 & 0 & 0.6 \\
\hline Progress towards the target of allocating $2 \%$ of national health budget on $\mathrm{R} 4 \mathrm{H}$ & 16 & 100 & 0 & 0.155 \\
\hline $\begin{array}{l}\text { Progress towards the target of allocating 5\% of health-related project funding on } \\
\text { research for health }\end{array}$ & 8 & 100 & 0 & 0.075 \\
\hline Existence of NGOs funding research & 0 & 100 & 0 & 0 \\
\hline Diversified research for health financial portfolio (public, industry, philanthropy) & 35 & 100 & 0 & 0.35 \\
\hline Sum of sub-function indices (E) & & & & 15.3 \\
\hline Total Number of sub-functions (F) & & & & 30 \\
\hline MNSR4HI $=[E / F) \times 100 \%$ & & & & 51 \\
\hline
\end{tabular}

meaning dead or non-existent; 10 had 1 to $49 \%$ denoting moribund; 5 had 50 to $69 \%$ indicating tepid, and 12 had 70 to $100 \%$ denoting flourishing. The average indices were $67 \%$ for the function of governance of $\mathrm{R} 4 \mathrm{H} ; 48.6 \%$ for creating and sustaining $\mathrm{R} 4 \mathrm{H}$ resources; $50.4 \%$ for producing and using $\mathrm{R} 4 \mathrm{H}$; and $23.6 \%$ for financing $\mathrm{R} 4 \mathrm{H}$.

Indices for individual sub-functions can aid the government to identify the reason for the sub-optimal performance of the $\mathrm{R} 4 \mathrm{H}$ system or a component and to 
develop relevant interventions to improve specific subfunctions.

After appraising the individual sub-function indices, the overall MNSR4HI was calculated as follows:

$$
\begin{aligned}
\text { MNSR4HI } & =\left(\frac{\sum_{i=1}^{30} S F I}{T N_{S F}}\right)=\left(\frac{15.3}{30}\right) \\
& =0.51 \times 100 \%=51 \%
\end{aligned}
$$

Where SFI is the sub-function index, $\sum_{i=1}^{30} S F I$ is the summation from $\mathrm{R} 4 \mathrm{H}$ sub-functions 1 to 30 , and $T N_{S F}$ is the total number of $\mathrm{R} 4 \mathrm{H}$ sub-functions, which is equal to 30 in this study.

Since the national $\mathrm{R} 4 \mathrm{H}$ index is measured on a scale of 0 (or $0 \%$ ) to 1 (or 100\%), the MNSR4HI of 0.51 (or $51 \%$ implies that Malawi's R4H performance is average.

The formula we developed for the national $\mathrm{R} 4 \mathrm{H}$ index is very similar to that used by the United Nations Development Programme to calculate the human development index [51]. It is also comparable to that used by Kirigia and Kirigia [52] in developing a Health Development Governance Index. In this paper we categorized national systems of $\mathrm{R} 4 \mathrm{H}$ with an overall index of $0 \%$ as dead or non-existent, those with a score of $1 \%$ to $49 \%$ as moribund, those with a score of $50 \%$ to $69 \%$ to be tepid, and those with a score of $70 \%$ to $100 \%$ to be flourishing. Since the MNSR4HI is within the $50 \%$ to $69 \%$ bracket, the Malawi national system of research for health is judged to be tepid. Of course, we consider this index as a rough indicator of the status of the Malawi national research for health system and as first step in its assessment. We expect other researchers to treat our study as a work-in-progress for debate and refinement so that a generally agreed-upon index can emerge for wide application in the African Region or globally. We also believe that even the indices for Malawi could be refined further if they were drawn up by a wider sample of $\mathrm{R} 4 \mathrm{H}$ researchers. It is our hope that this index process will trigger heated debate globally.

\section{Summary}

A functional NHRS is a prerequisite for the achievement of health system goals of improving health and health equity in ways that are responsive, financially fair, and make the most efficient use of available resources [53]. Volmink and Dare [54] characterized African research and by implication national health research systems - as moribund. In our view, however, the Malawi government, with partner support, has made substantive effort to strengthen capacities of individuals and institutions that generate scientific knowledge, and so we consider its NHRS as tepid with significant potential to flourish.
As shown in Figure 2, the MNSR4HI is $51 \%$, which is within the $50 \%-69 \%$ range.

\section{RH4 governance}

Governance of $\mathrm{R} 4 \mathrm{H}$ has improved with the promulgation of the Malawi Science and Technology Act in 2003; the establishment of the NCST to regulate the conduct of research and the National Health Sciences Research Committee and COMREC to ensure technical and ethical rigor of research protocols and proposals; and development of a national health research agenda. However, lack of an explicit $\mathrm{R} 4 \mathrm{H}$ policy, a strategic plan or a national health research management forum greatly undermines the government's effectiveness in supervising the NHRS.

\section{Developing and sustaining $\mathrm{R} 4 \mathrm{H}$ resources}

Malawi has a national health research focal point and a $\mathrm{R} 4 \mathrm{H}$ program housed within the Ministry of Health. There are four public and 11 private universities, which could be pillars upon which requisite $\mathrm{R} 4 \mathrm{H}$ capacities could be built. Efforts are under way in the Ministry of Health to strengthen the functionality of the health management information system to facilitate the conduct of implementation research. In our view, the Malawi government with partner support has made substantive effort to strengthen capacities of individuals and institutions that generate scientific knowledge. However, as acknowledged in various government documents and articles published by Malawian researchers, much more remains to be done to strengthen the capacities of both public and private institutions of higher learning to increase $\mathrm{R} 4 \mathrm{H}$ publications.

\section{Producing and using R4H}

The health research program does not undertake research by itself. During the period 2005-2012 the University of Malawi published 215 articles on various aspects of public health. Uthman and Uthman's [41] analysis of African countries' biomedical papers indexed by PubMed between 1996 and 2005 revealed that Malawi had a total of 450 articles, which earned it a rank of 15 among African countries. Gondwe and Kavinya's [43] search of the MEDLINE/PubMed database found 489 articles on health originating from Malawi. A Malawian scholar [44] has argued that while there has been growth in the number of publications, efforts need to be intensified to boost research productivity in the country. So far the utilization of research findings in policy development and public practice can best be described as tepid. However, use of knowledge from research in decision making is expected to improve in the medium and long term with the creation of the knowledge translation platform. 


\section{Financing}

$\mathrm{R} 4 \mathrm{H}$ is primarily financed by the Government of Malawi and international nongovernmental organizations and to a lesser extent by multilateral and bilateral donors. The Ministry of Health has a budget line for research for health. The budget planned for research for the five financial years $2011 / 12-2015 / 16$ is approximately $0.26 \%$ of the total government budget of 252154 million kwacha [2]. The level of funding for $\mathrm{R} 4 \mathrm{H}$ is far lower than $2 \%$ of the national health budget, the level recommended by the Commission on Health Research for Development [48].

\section{Ethical clearance}

The study was exempted from review by the Malawi COMREC based on the understanding that it would be based solely on existing public data, documents and records and completion of the questionnaire by the two Malawian co-authors.

\begin{abstract}
Abbreviations
CHAM: Church Association of Malawi; COMREC: College of Medicine Research and Ethics Committee; Int\$: International dollars or purchasing power parity; MNSR4HI: Malawi national system of research for health index; NCST: National Commission for Science and Technology; NHRI: National Health Research Institute; R4H: Research for health; SFI: Sub-function index; WHO: World Health Organization.
\end{abstract}

\section{Competing interests}

The authors declare that they have no competing interests.

\section{Authors' contributions}

JMK contributed to the study design, analysis and writing of various sections of the manuscript. DDK, ASM and MMOO contributed to data analysis and writing of various sections of the manuscript. All authors read and approved the final manuscript.

\section{Acknowledgements}

Jehovah Nissi met all our needs during the entire study. We are grateful to BMC peer reviewers for suggestions that helped to improve the quality of the debate paper; and to Ms Kellen Kebaara for editing the manuscript. The views expressed in this manuscript are entirely those of the authors and should not be attributed in any manner to the organizations they work for.

\section{Author details}

${ }^{1}$ Research, Publications and Library Services Programme, Health Systems and Services Cluster, World Health Organization, Regional Office for Africa, Brazzaville, Congo. ${ }^{2}$ Ministry of Health, Department of Research, Lilongwe, Malawi. ${ }^{3}$ Department of Community Health, Faculty of Public Health and Family Medicine, College of Medicine, Blantyre, Malawi.

Received: 6 May 2014 Accepted: 16 March 2015

Published online: 31 March 2015

\section{References}

1. World Health Organization (WHO). World Health Statistics 2013. Geneva; 2013.

2. Government of Malawi, Ministry of Health. Malawi health sector strategic plan 2011-2016. Lilongwe; 2011.

3. University of Washington, Institute for Health Metrics and Evaluation. Global Burden of Disease Database. http://www.healthmetricsandevaluation.org/ search-gbd-data.

4. World Health Organization (WHO). World health statistics 2012. Geneva; 2012.

5. World Health Organization (WHO). World health report 2010 - health systems financing: the path to universal coverage. Geneva; 2010.
6. World Health Organization (WHO). Global health observatory http://apps. who.int/gho/data/view.main.1900ALL?lang=en.

7. WHO. The world health report 2013: research for universal health coverage Geneva: WHO; 2013.

8. Task Force on Health Systems Research. Informed choices for attaining the millennium development goals: towards an international cooperative agenda for health systems research. Lancet. 2004;364:997-1003.

9. World Health Organization Regional Office for Africa. Health research: agenda for the WHO African Region. Brazzaville; 2006.

10. World Health Organization (WHO). The WHO strategy on research for health. The 2010 sixty-third World Health Assembly Geneva; 2012.

11. World Health Organization and Government of Mali. The Bamako Call for Action on Research for Health: Strengthening research for health, development, and equity. From the Global Ministerial Forum on Research for Health, Bamako, Mali, 17-19 November, 2008. Geneva; 2008.

12. World Health Organization Regional Office for Africa. The Algiers declaration on research - Ministerial Conference on Research for Health in the African Region: Narrowing the knowledge gap to improve Africa's health,

23-26 June 2008. Brazzaville; 2008.

13. World Health Organization (WHO). High Level Ministerial Meeting on Health Research in Africa: Communique, Abuja, Nigeria, 8-10 March 2006. Geneva; 2006.

14. World Health Organization (WHO). High Level Ministerial Meeting on Health Research for Disease Control and Development: Communique, Accra, Ghana, 15-17 June 2006; 2006.

15. World Health Organization (WHO). Ministerial Summit on Health Research. World Health Assembly Resolution WHA58.34. Geneva; 2005.

16. World Health Organization (WHO) and Government of Mexico. Report from the Ministerial Summit on Health Research: Identify challenges, inform actions, correct inequities. Mexico City, 16-20 November 2004. Geneva; 2004.

17. World Health Organization Regional Office for Africa. Strategic Health Research Plan 1999-2003. Brazzaville; 1998.

18. Pang T, Sadana R, Hanney S, Bhutta ZA, Hyder AA, Simon J. Knowledge for better health - a conceptual framework and foundation for health research systems. Bull World Health Organ. 2003;81(11):815-20.

19. Kirigia JM, Wambebe C. Status of national health research systems in ten countries of the WHO African Region. BMC Health Serv Res. 2006;6:135 URL: http://www.biomedcentral.com/1472-6963/6/135.

20. Mbondji PE, Kebede D, Zielinski C, Kouvividila W, Sanou I, Lusamba-Dikassa P-S. Overview of national health research systems in sub-Saharan Africa: results of a questionnaire-based survey. J R Soc Med. 2014;107(IS):46-54.

21. Senkubuge F, Mayosi BM. The state of the national health research system in South Africa. In: South African Health Review 2012/13. Edited by A. Padarath and R. English. Durban: Health Systems Trust; 2013:141-150.

22. Government of Malawi. Malawi Science and Technology Act. Lilongwe; 2003.

23. National Commission on Science and Technology (NCST), Malawi. http://www.ncst.mw/.

24. Government of India, Department of Health Research. Annual Report 2011-2012. Bombay; 2012

25. World Health Organization Regional Office for Africa. Guidelines for developing national health policies and plans. Brazzaville; 2005.

26. Smith R. A national health research policy. BMJ. 1988;297:805-6.

27. Becerra-Posada F, Kennedy A, IJsselmuiden C. COHRED Record Paper 8. Best practices in health research policy development: Lessons from an expert consultation. Council on Health Research for Development (COHRED); 2008

28. Republic of South Africa, Department of Health. Health research policy in South Africa. Pretoria; 2001.

29. World Health Organization Regional Office for Europe. Research policy for health for all. Copenhagen; 1988.

30. Editorial. The Bamako Call to Action: research for health. Lancet. 2008;372(9653):1855.

31. Pouris A. Science in South Africa: the dawn of a renaissance? South African Journal of Science 2012; 108(7/8) http://dx.doi.org/10.4102/sajs. v108i7/8.1018].

32. Thomas L. Capacity building for local NGOs: A guidance manual for good practice. London: Catholic Institute for International Relations; 2005.

33. List_of_universities_in_Malawi. http://en.wikipedia.org/wiki/ List_of_universities_in_Malawi. 
34. Consejo Superior de Investigaciones Científicas (CSIC). Webometrics Ranking of World Universities. Madrid: CSIC; 2014. http://www.webometrics.info/en/ Africa/Malawi.

35. Nachega JB, Uthman OA, Ho Y-S, Lo M, Anude C, Kayembe P, et al. Current status and future prospects of epidemiology and public health training and research in the WHO African Region. Int J Epidemiol. 2012:41:1829-46.

36. NCST. Health research capacity strengthening initiative http://www.ncst. mw/index.php/projects/hrcsi.

37. Phiri K, Kalirani-Phiri L. Gap analysis for the national health research agenda of Malawi: research priorities for the themes of infectious and non-infectious Diseases. Lilongwe: National Commission for Science and Technology; 2012.

38. Nyirenda L, Kwalamasa K, Cole DC, Fazal N. HRSCI Programme Evaluation August-October 2013. Lilongwe: National Commission for Science and Technology; 2013

39. Mayosi BM, Mekwa JN, Blackburn J, Coovadia H, Freedman IB, Jeenah M, et al. Strengthening research for health, innovation and development in South Africa: Proceedings and recommendations of the 2011 national health research summit. Pretoria: Department of Health; 2012. p. 1-9.

40. Kakhongwe P. Inventory of University of Malawi Studies Published in International Journal, 2005-2012. Zomba: Centre for Social Research; 2013.

41. Uthman OA, Uthman MB. Geography of Africa biomedical publications: an analysis of 1996-2005 PubMed papers. Int J Health Geogr. 2007;6:46. URL: http://ij-healthgeographics.com/content/6/1/46.

42. Muula AS. Status of scholarly productivity among nursing academics in Malawi. Croat Med J. 2007:48:568-73.

43. Gondwe M, Kavinya T. An analysis of Malawi's publication productivity. Malawi Med J. 2008;90:92-34

44. Muula AS. Malawi's health publication productivity - a response and where do we go from here? Malawi Med J. 2009; 21(1) (Editorial).

45. Schneider JW. Bibliometric research performance indicators for the Nordic countries: 1989-2008. Copenhagen: Royal School of Library and Information Science, Denmark; 2008.

46. World Bank and Elsevier. A decade of development in sub-Saharan African science, technology, engineering and mathematics research. Washington, DC: The World Bank and Elsevier; 2014.

47. Government of Malawi. 2012/13 expenditure estimates. Lilongwe: MOH; 2014.

48. Commission on Health Research for Development. Health research: essential link to equity in development. New York: Oxford University Press; 1990.

49. Organisation for Economic Cooperation and Development (OECD). Frascati Manual - proposed standard practice for surveys on research and experimental development. Paris: OECD; 2002.

50. OECD. Measuring R \& D in developing countries - Annex to the Frascati Manual. Paris: OECD; 2012.

51. United Nations Development Programme. Human Development Report 2003: Millennium Development Goals: a compact among nations to end poverty. New York: Oxford University Press; 2003.

52. Kirigia JM, Kirigia DG. The essence of governance in health development. Int Arch Med. 2011:4:11. URL: http://www.biomedcentral.com/content/pdf/ 1755-7682-4-11.pdf.

53. World Health Organization. Strengthening health systems to improve health outcomes. Geneva: WHO; 2007.

54. Volmink J, Dare L. Addressing inequalities in research capacity in Africa. BMJ. 2005:331:705-6.

\section{Submit your next manuscript to BioMed Central and take full advantage of:}

- Convenient online submission

- Thorough peer review

- No space constraints or color figure charges

- Immediate publication on acceptance

- Inclusion in PubMed, CAS, Scopus and Google Scholar

- Research which is freely available for redistribution 